\title{
Polymorphisms of glutathione S-transferases (GST) and thymidylate synthase (TS) - novel predictors for response and survival in gastric cancer patients
}

\author{
E Goekkurt ', , S Hoehn', C Wolschke', C Wittmer ${ }^{3}$, C Stueber', DK Hossfeld' and J Stoehlmacher ${ }^{*, 1,2}$ \\ 'Department of Haematology and Oncology, University Hospital Hamburg Eppendorf, University of Hamburg, Germany; ${ }^{2}$ Department of Internal \\ Medicine I, University Hospital Carl Gustav Carus, University Dresden, Germany; ${ }^{3}$ Department of Pathology, University Hospital Hamburg Eppendorf, \\ University of Hamburg, Germany
}

\begin{abstract}
To evaluate the predictive value of a panel of gene polymorphisms involved in metabolism of 5-FU and cisplatin on clinical outcome in advanced gastric cancer patients. A total of 52 patients were enrolled in this study. DNA was extracted from paraffin-embedded tumour specimen. Genotypes were determined using PCR-RFLP. Median survival time was 6.0 months (95\% Cl 3.9;8.I). Overall response rate was $26 \%$. Patients possessing the glutathione S-transferase PI- 105 Valine/Valine (GSTPI- I05VV) genotype showed a response rate of $67 \%$ compared to $21 \%$ in patients harbouring at least one GSTPI- 105 Isoleucine (GSTPI - I05I) allele $(P=0.038)$. GSTPI - I05W patients demonstrated a significant superior median survival time of 15.0 months (95\% Cl 7.8;22.0) compared to 6.0 months $(95 \% \mathrm{CI} 5.1 ; 7.0)$ in patients with at least one GSTPI-I05I allele $(P=0.037)$. Patients possessing a favourable thymidylate synthase (TS) genotype (2R/2R, 2R/3RC, 3RC/3RC) experienced a superior survival time of 10.2 months (95\% Cl 5.1;15.3) compared to 6.0 months $(95 \% \mathrm{Cl} 5.0 ; 7.0)$ in patients with unfavourable TS genotypes $(P=0.099)$. Patients harbouring the GSTPII05ll genotype and one of the unfavourable TS genotypes showed an inferior median survival time of 6.0 months (95\% Cl 3.9;8.1) compared to II months $(95 \% \mathrm{Cl} 6,23 ; 15,77)$ in patients with either GSTPI- I05W or a favourable TS genotype $(P=0.044)$. Testing for TS and GSTPI polymorphisms may allow identification of gastric cancer patients who will benefit from 5-FU/cisplatin chemotherapy, sparing others the side effects of this chemotherapy.

British Journal of Cancer (2006) 94, 28 I-286. doi: I0.1038/sj.bjc.660289 I www.bjcancer.com

Published online 29 November 2005

(c) 2006 Cancer Research UK
\end{abstract}

Keywords: glutathione S-transferase PI; thymidylate synthase; pharmacogenetics; gastric cancer; 5-FU/cisplatin

Worldwide, gastric cancer is the fourth common type of cancer and the second most frequent cause of death from cancer. The median survival time of patients with advanced gastric cancer ranges approximately from 7.5 to 12 months (Parkin, 2001). 5-FU/ cisplatin has been referred to as a standard chemotherapy in gastric cancer patients for many years. During the last few years additional drugs were introduced into chemotherapy regimens for gastric cancer such as oxaliplatin, the taxanes and irinotecan. Results from phase II studies indicate a promising efficacy and managable toxicity profile for combination chemotherapies including these new substances (Al-Batran et al, 2004; Bouche et al, 2004; Chao et al, 2004; Lee et al, 2004; Park et al, 2004; Souglakos et al, 2004; Van Cutsem, 2004). One of the remaining challenges is the development of predictive marker profiles to identify patients who will derive both minimal toxicity and maximum benefit from certain chemotherapy.

There is a growing body of evidence suggesting that genetic polymorphisms in genes involved in metabolism, signalling,

\footnotetext{
*Correspondence: Dr J Stoehlmacher;

E-mail: jan.stoehlmacher@uniklinikum-dresden.de

Received 8 August 2005; revised 12 October 2005; accepted 27 October 2005; published online 29 November 2005
}

transport, DNA-repair and cellular response pathways all contribute to inter-patient variability of drug response and toxicity. Pharmacogenetic analyses appear to be a promising tool to develop individualised treatment plans.

Fluoropyrimidines remain an important drug in the chemotherapeutic treatment of gastric cancer. Decreased levels of the target enzyme thymidylate synthase (TS) have been repeatedly associated with superior clinical outcome in gastrointestinal cancers, including stomach cancer (Leichman et al, 1995; Boku et al, 1998; Shirota et al, 2001). TS catalyses the formation of thymidylate, a source of DNA replication, from dUMP (Danenberg, 1977). A repeat polymorphism within the $5^{\prime}$ untranslated region (UTR), that alters TS expression was correlated with response and survival in colorectal cancer patients receiving 5-FU in several studies (Horie et al, 1995; Kawakami et al, 1999; Iacopetta et al, 2001; Pullarkat et al, 2001; Marsh et al, 2001). Recently, a novel functional G/C single nucleotide polymorphism (SNP) within this repeat polymorphism was identified (Kawakami and Watanabe, 2003; Mandola et al, 2003). This G/C SNP causes a disruption of the binding site of the transcription factor USF-1 thereby altering TS expression. A recent report in colorectal cancer indicates the clinical significance of the G/C SNP (Marcuello et al, 2004). Finally, a 6-bp deletion polymorphism within the $3^{\prime}$ UTR of the TS gene has been described (Ulrich et al, 2000) that also alters TS 
expression, although the exact underlying mechanism remains unclear at this time (Mandola et al, 2004). In addition to polymorphisms of the TS gene, the common MTHFR-C677T polymorphism has been associated with response to $5-\mathrm{FU}$ in colorectal tumours (Cohen et al, 2003; Etienne et al, 2004). Methylene tetrahydrofolate reductase (MTHFR) plays a central role in folate metabolism. The substrate for MTHFR, 5,10-MTHF, is used for the synthesis of dTMP by TS.

Glutathione-S-transferases are crucial for the cell defence system. These phase II detoxification enzymes are involved in detoxification of a variety of chemotherapeutics including platinum. The GSTP1 isoform has been detected at high levels within the gastrointestinal tract. In addition, in vitro analyses revealed a significant association between high GSTP1 expression of tumour cells and decreased sensitivity to platinum agents (Oguri et al, 2000). An A/G SNP located within the substrate-binding domain of GSTP1, at position +313 within exon 5 , results in an amino-acid substitution of Isoleucine by Valine (Ile105Val). This polymorphism significantly influences enzyme activity (Zimniak et $a l, 1994)$ and is linked to clinical outcome of patients who received platinum-based chemotherapy (Stoehlmacher et al, 2002, 2004). GSTM1 and GSTT1 deletion polymorphisms (null genotypes) have also been reported to be associated with diminished GST enzyme activity (London et al, 2000).

Genes of the nucleotide-excision-repair (NER) pathway plays a key role in recognition and repair of damaged DNA caused by platinum compounds. Important members of the NER pathway, namely excision-repair-cross-complementing gene 1 and 2 (ERCC1 and ERCC2), the latest also named Xeroderma pigmentosum complementation group D (XPD) exhibit several polymorphic sites. Functional polymorphisms of both genes (ERCC1 - C118T and ERCC2 - Gln751Lys) have been demonstrated to impact clinical outcome of patients receiving platinum-based chemotherapy (Shen et al, 1998; Park et al, 2001; Isla et al, 2004).

In the current analysis, we studied a panel of nine genetic polymorphisms within seven genes (TS, MTHFR, GSTP1, GSTT1, GSTM1, ERCC1, ERCC2) involved in the metabolism of cisplatin and 5-FU as well as genes of the NER. We tested the hypothesis whether these polymorphisms, alone or in combination, may have the potential to predict response and survival in patients with advanced gastric cancer receiving 5-FU/cisplatin combination chemotherapy.

\section{PATIENTS AND METHODS}

\section{Subjects}

All patients included in this study had advanced gastric cancer and were treated between 2002 and 2004 at the Department of Oncology at the University Hospital Hamburg Eppendorf, Germany. All patients received at least one complete cycle of 5FU/cisplatin/FA as first-line chemotherapy. One cycle consisted of biweekly cisplatin $50 \mathrm{mg} \mathrm{m}^{-2}$ ( $1 \mathrm{~h}$ infusion) and weekly FU $2 \mathrm{~g} \mathrm{~m}^{-2}$ ( $24 \mathrm{~h}$ continuous infusion) and FA $500 \mathrm{mg} \mathrm{m}^{-2}$ (2-h intravenous infusion) for 6 weeks. Response evaluation was performed every 6 weeks using CT scanning based on RECIST criteria. Responses were confirmed after 4 weeks. All patients agreed to perform genotype analyses in this study.

\section{Extraction of DNA}

Paraffin-embedded tumour specimens for genotype analyses were available from 52 patients with advanced gastric cancer. Genomic DNA was extracted from representative sections (at least $80 \%$ of tumour infiltration) of formalin-fixed, paraffin-embedded tumour specimen using the QiaAmp kit (Qiagen, Valencia, CA, USA).
Representative tumour sections were selected after evaluation (light microscopy) by the pathologist (CW).

\section{Study design}

Genotyping was carried out by using PCR-based RFLP protocols as described previously. The following genetic polymorphisms were analysed: glutathione S-transferase (GSTP1 - Ile105Val, GSTT1 and GSTM1 deletion), thymidylate synthase (TS-5' UTR 2R/3R; TS-5' G/C; TS-3' UTR 1494del6), methylene-tetrahydofolatereductase (MTHFR - C677T), excision repair cross-complementing gene 1 and 2 (ERCC1 - C118T and ERCC2 - Gln751Lys) (Frosst et al, 1995; Arand et al, 1996; Lunn et al, 2000; Mandola et al, 2003; Stoehlmacher et al, 2004). The PCR reaction volume was $25 \mu \mathrm{l}$ and restricted PCR fragments were separated on a 3\% agarose gel. PCR/ RFLP analyses were performed by a technician blinded for the clinical data. For quality purposes $20 \%$ random samples of each genotype were repeated.

A comprehensive chart review was performed to obtain all necessary demographic and clinical information including age, sex, involved metastatic sites, objective tumour response rate and survival. Survival was measured from the beginning of 5-FU/ cisplatin chemotherapy until death from any cause.

\section{Statistical analyses}

Statistical analyses were carried out using SPSS for Windows (Version 13.0). Fisher's exact test (two-sided) and $\chi^{2}$ test were used to assess the association between each genotype and clinical response to 5-FU/cisplatin chemotherapy. The log-rank test (Miller, 1981) and Kaplan-Meier plots (Kaplan and Meier, 1958) were used to evaluate the association of genotypes and overall survival. Statistical significance was interpreted as $P<0.05$.

\section{RESULTS}

In this retrospective study, 52 Caucasian patients consisting of 18 females (35\%) and 34 males (65\%) were analysed. Patients' demographics and disease characteristics at baseline are given in Table 1. The median follow-up time was 6.2 months (95\% CI 4.6; 7.4). Median survival time was 6.0 months ( $95 \%$ CI 3.9; 8.1). None of these patients were referred for definitive surgery after application of chemotherapy. Two patients were excluded from response evaluation, because the response confirmation after 4 weeks was not documented in the medical chart. In all, $26 \%$ of patients (13/50) showed a response (partial response (PR) or complete response (CR)) to 5-FU/cisplatin chemotherapy. The majority of patients $(37 / 50,74 \%)$ demonstrated stable disease (SD) or progressive disease (PD).

Genotypes could be determined as follows: GSTP1 50/52 (96\%), GSTM1 and GSTT1 52/52 (100\%), ERCC1 51/52 (98\%), ERCC2 51/ 52 (98\%), MTHFR-677 52/52 (100\%), TS-5' UTR 45/52 (87\%), TS$5^{\prime}$ UTR G-C SNP 43/52 (83\%) and TS-3' 41/52 (79\%). Distribution of genotypes and responses of the available 50 patients is given in Table 2.

\section{Association between GSTP1-105 polymorphism and response and survival}

GSTP1-105 genotype analyses were successful for 50 patients of which 48 were eligible for response analyses.

For association analysis of genotype and response to chemotherapy patients with CR and PR were determined 'responders' and patients with SD and PD were referred to as 'nonresponders'. According to previous data (Stoehlmacher et al, 2004) patients were divided into a favourable (homozygous GSTP1-105Val) and an unfavourable genotype group (heterozygots and homozygous 
Table I Patient's demographics and disease characteristics at baseline

\begin{tabular}{lcc}
\hline & $\boldsymbol{n}$ & $\%$ \\
\hline $\begin{array}{l}\text { Age (years) } \\
\text { Range }\end{array}$ & 56 & - \\
Gender & $27-82$ & \\
$\quad$ Male & & 65 \\
Female & 34 & 35 \\
Karnofski index & 18 & \\
100-90 & & 52 \\
$80-70$ & 27 & 48 \\
& 25 & 13 \\
Number of involved sites & & 35 \\
I & & 52 \\
2 & 7 & \\
$\geqslant 3$ & 18 & 71 \\
Previous surgery & 27 & 29 \\
Yes & & 6 \\
No & 37 & \\
& & \\
Prior adjuvant chemotherapy & 15 & \\
Yes & & \\
No & 3 & \\
\hline
\end{tabular}

GSTP1-105Ile). Patients possessing the GSTP1-105 Val/Val genotype showed a significant superior response rate of $67 \%(4 / 6)$ compared to only $21 \%(9 / 42)$ in patients harbouring at least one GSTP1-105Ile allele ( $P=0.038$, Fisher's exact test) (Table 3$)$. None of the patients homozygous for the GSTP1-105Val allele showed disease progression.

Patients with GSTP1-105 Val/Val genotype demonstrated significant superior median survival time with 15.0 months $(95 \%$ CI $7.8 ; 22.0)$ compared to only 6.0 months $(95 \%$ CI $5.1 ; 7.0)$ for patients with at least one GSTP1-105Ile allele $(P=0.038$, log-rank test) (Figure 1).

\section{Association between TS polymorphisms and outcome to 5-FU/cisplatin chemotherapy}

Both, the TS-3' UTR (6-bp deletion) polymorphism and the polymorphisms in the $5^{\prime}$ UTR (28bp repeat + G/C SNP) were not associated with response to chemotherapy.

However, combined analysis of polymorphisms in the TS-5' UTR showed a trend for superior survival in patients harbouring a favourable TS-5' UTR genotype. The favourable TS-5' UTR genotype group included those genotypes that have been linked to decreased TS expression; 2R/2R, 2R/3RC, 3RC/3RC. Whereas the unfavourable group consisted of TS genotypes associated with elevated TS levels: 2R/3RG, 3RC/3RG and 3RG/3RG (Mandola et al, 2003; Marcuello et al, 2004). The favourable group experienced a superior median survival time of 10.2 months (95\% CI $5.1 ; 15.3$ ) compared to only 6.0 months $(95 \%$ CI $5.0 ; 7.0)$ in the unfavourable genotype group $(P=0.099$, log-rank test).

\section{Combined analysis of GSTP1 and TS-5' genotypes and survival}

Based on the results of superior survival observed for the favourable GSTP1-105 genotype group and the favourable TS- $5^{\prime}$ UTR genotype group in the univariate analysis, a combined analysis for survival was performed.

All genotypes (GSTP1-105, TS- $5^{\prime}$ repeat and TS5'-SNP) could be identified in 41 of 52 patients $(79 \%)$. Patients were divided into three groups: patients possessing neither GSTP1 Val/Val nor one
Table 2 Distribution of genotypes and responses

\begin{tabular}{|c|c|c|c|c|}
\hline & \multirow[b]{2}{*}{ Total n (\%) } & \multicolumn{2}{|c|}{ Responder Nonresponder } & \multirow[b]{2}{*}{$P$-value ${ }^{a}$} \\
\hline & & $n(\%)$ & $n(\%)$ & \\
\hline All & $50(100)$ & $13(26)$ & $37(74)$ & - \\
\hline \multicolumn{5}{|l|}{ TS-5'UTR } \\
\hline $2 R / 2 R$ & $13(26)$ & $2(15)$ & II (85) & \\
\hline $2 R / 3 R$ & $19(38)$ & 7 (37) & $12(63)$ & \\
\hline $3 R / 3 R$ & $12(24)$ & $3(25)$ & $9(75)$ & 0.400 \\
\hline Missing & $6(12)$ & & & \\
\hline \multicolumn{5}{|l|}{ TS-5' UTR+G/C SNP } \\
\hline $2 / 2,2 / 3 C, 3 C / 3 C$ & $23(46)$ & $5(22)$ & $18(78)$ & \\
\hline $2 / 3 \mathrm{G}, 3 \mathrm{C} / 3 \mathrm{G}, 3 \mathrm{G} / 3 \mathrm{G}$ & $20(40)$ & $7(35)$ & $13(65)$ & 0.334 \\
\hline Missing & $7(14)$ & & & \\
\hline \multicolumn{5}{|l|}{ TS-3' 1494del6 } \\
\hline$-6 /-6$ & $12(24)$ & $5(42)$ & $7(58)$ & \\
\hline$-6 / 6$ & $23(46)$ & $6(26)$ & $17(74)$ & \\
\hline $6 / 6$ & $5(10)$ & I (20) & $4(80)$ & 0.553 \\
\hline Missing & $10(20)$ & & & \\
\hline \multicolumn{5}{|l|}{ GSTPI - 105} \\
\hline \|le/lle & $30(60)$ & $7(23)$ & $23(77)$ & \\
\hline$\| \mathrm{e} / \mathrm{Val}$ & $12(24)$ & $2(17)$ & $10(83)$ & \\
\hline $\mathrm{Val} / \mathrm{Val}$ & $6(12)$ & $4(67)$ & $2(33)$ & 0.060 \\
\hline Missing & $2(4)$ & & & \\
\hline \multicolumn{5}{|l|}{ GSTMI } \\
\hline GSTMI- & $32(64)$ & $9(28)$ & $23(72)$ & \\
\hline GSTMI+ & $18(36)$ & $4(22)$ & 14 (78) & 0.648 \\
\hline Missing & $0(0)$ & & & \\
\hline \multicolumn{5}{|l|}{ GSTTI } \\
\hline GSTTI- & $38(76)$ & $8(2 \mid)$ & $30(79)$ & \\
\hline GSTTI+ & $12(24)$ & $5(42)$ & $7(58)$ & 0.156 \\
\hline Missing & $0(0)$ & & & \\
\hline \multicolumn{5}{|l|}{$E R C C 1-118$} \\
\hline $\mathrm{C} / \mathrm{C}$ & $5(10)$ & $2(40)$ & $3(60)$ & \\
\hline $\mathrm{C} / \mathrm{T}$ & $26(52)$ & $6(23)$ & $20(77)$ & \\
\hline $\mathrm{T} / \mathrm{T}$ & $18(36)$ & $5(28)$ & $13(72)$ & 0.727 \\
\hline Missing & I (2) & & & \\
\hline \multicolumn{5}{|l|}{ ERCC2-75I } \\
\hline $\mathrm{Gln} / \mathrm{Gln}$ & $12(24)$ & $3(25)$ & $9(75)$ & \\
\hline Gln/Lys & $25(50)$ & $8(32)$ & $17(68)$ & \\
\hline Lys/Lys & $12(24)$ & $2(17)$ & $10(83)$ & 0.607 \\
\hline Missing & I (2) & & & \\
\hline \multicolumn{5}{|l|}{ MTHFR-677 } \\
\hline $\mathrm{C} / \mathrm{C}$ & $28(56)$ & $10(36)$ & $18(64)$ & \\
\hline $\mathrm{C} / \mathrm{T}$ & $20(40)$ & $2(10)$ & $18(90)$ & \\
\hline $\mathrm{T} / \mathrm{T}$ & $2(4)$ & I (50) & I (50) & 0.099 \\
\hline Missing & $0(0)$ & & & \\
\hline
\end{tabular}

50 of 52 patients (96\%) were evaluable for response. Two pts were excluded for response evaluation due to missing response confirmation (MRC). For association analysis of genotype and response to chemotherapy patients with complete response (CR) and partial response (PR) were determined 'responder' and patients with stable disease (SD) and progressive disease (PD) were referred to as 'non-responder'. ${ }^{a} \chi^{2}$ test.

of the favourable TS-5' UTR genotypes (group A, $n=15(37 \%)$ ), patients harbouring either GSTP1 Val/Val or a favourable TS- $5^{\prime}$ UTR genotype (group B, $n=23(56 \%)$ ) and patients with GSTP1$105 \mathrm{Val} / \mathrm{Val}$ and a favourable TS-5' UTR genotype (group C, $n=3$ $(7 \%)$ ). Owing to the small size of group $C$, this group was combined with group B for survival analyses. Group B and C patients combined demonstrated a superior median survival time of 11.0 months $(95 \%$ CI 6,$23 ; 15,77)$ compared to only 6.0 months 
Table 3 Association between GSTPI-I05 genotype and response to 5 FU/cisplatin chemotherapy in patients with advanced gastric cancer

\begin{tabular}{|c|c|c|c|c|c|}
\hline & \multirow[b]{2}{*}{ Total (n) } & \multicolumn{2}{|c|}{ Responders } & \multicolumn{2}{|c|}{ Nonresponders } \\
\hline & & No. & $\%$ & No. & $\%$ \\
\hline \multicolumn{6}{|l|}{ Genotype } \\
\hline $\begin{array}{l}\mathrm{Val} / \mathrm{Val} \\
\mathrm{Val} / / \mathrm{le}+\end{array}$ & 6 & 4 & 67 & 2 & 33 \\
\hline lle/lle & 42 & 9 & 21 & 33 & 79 \\
\hline
\end{tabular}

$P=0.038$ (Fisher's exact test, two-sided) for genotype - response association.

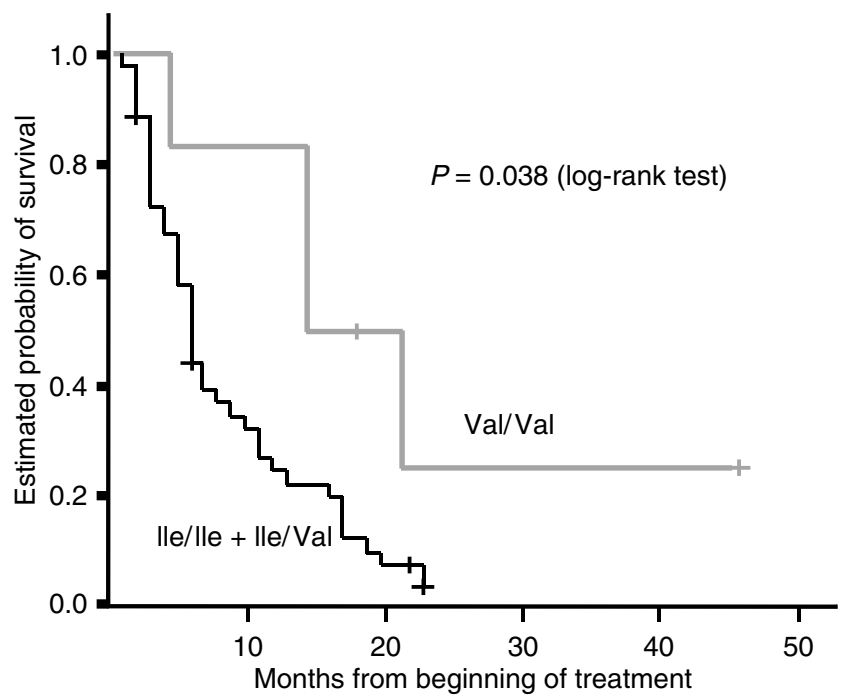

Figure I Association between GSTPI-105 genotypes and overall survival in patients with advanced gastric cancer.

(95\% CI $3.9 ; 8.1)$ for group A patients $(P=0.044$, log-rank test, Figure 2). Two patients of group $C$ were still alive at time of analyses with a survival time of 18 and 22 months, respectively. The third patient of this group died 15 months after start of 5-FU/ cisplatin chemotherapy.

No associations between any of the polymorphisms TS- $3^{\prime}$ 1494del6, MTHFR - C677T, GSTM1, GSTT1, ERCC1 - C118T or ERCC2 - Gln751Lys and response (Table 2) or overall survival were found.

\section{DISCUSSION}

We attempted to identify predictive genetic polymorphisms for response and survival to 5-FU/cisplatin chemotherapy in patients with advanced gastric cancer. In our study, the GSTP1-105 polymorphism was identified as a predictive and a prognostic marker in gastric cancer patients. Cisplatin (CDDP), widely used in the treatment of solid tumours, is in part detoxified by glutathione S-transferase P1 (GSTP1). The GSTP1-105Val allele was significantly associated with increased response rate and superior survival in the current study. The insufficient formation of CDDP-Glutathione (CDDP-GSH) adducts, the detoxified form of CDDP, was postulated as mechanism for the protective effect of the GSTP1-105Val variant. Goto et al (1999) provided evidence for the direct involvement of GSTP1 in the detoxification of CDDP by forming CDDP-GSH adducts. Transfection of GSTP1 cDNA into human colon cancer cells resulted in an increase of GSTP1 expression and an augmentation of DDP-GSH adduct formation

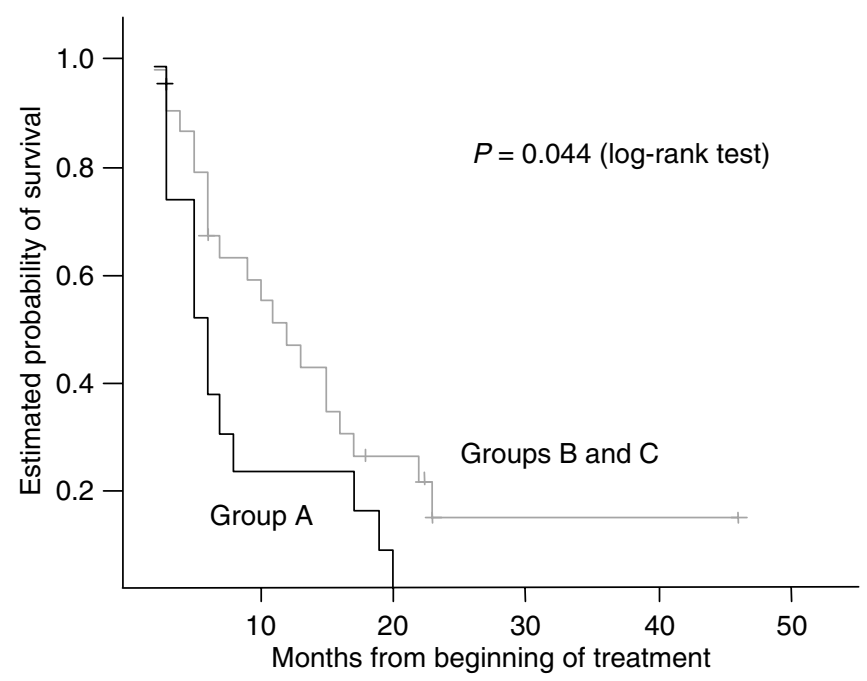

Figure 2 Association between combined analyses of GSTPI-I05 and TS-5' UTR polymorphisms including the TS-5' G-C SNP and overall survival among patients with advanced gastric cancer. Group A includes patients with only unfavourable genotypes in both genes $(n=15)$. Group B includes either patients homozygous for the GSTPI-I05 Val variant or patient with a favourable TS-5' UTR genotype $(n=23)$ and group $C$ patients are homozygous for GSTPI-I05 Val and possess a favourable TS-5' UTR polymorphism $(n=3)$.

(Goto et al, 1999). In addition, transfection analyses reported by Ban et al (1996) showed an association between GSTP1 and both acquired and intrinsic resistance to cisplatin (Ban et al, 1996). As a result of impairment of the GSTP1 substrate binding capacity caused by the underlying $A \rightarrow G$ substitution, patients homozygous for the GSTP1-105 valine variant may accumulate more drug compared to patients possessing one or two wild-type alleles (Watson et al, 1998). These results are in agreement with reports linking high GSTP1 mRNA expression to improved survival in oesophageal cancer patients. Among patients with oesophageal cancer, who received a 5-FU/cisplatin combination chemotherapy and radiation, those patients with decreased intratumoral GSTP1 levels demonstrated significant superior survival (Joshi et al, 2005). Additionally, reports in colorectal cancer patients demonstrated a significantly improved time to progression and overall survival for carriers of the GSTP1-105Val allele after 5-FU/ oxaliplatin chemotherapy (Stoehlmacher et al, 2002, 2004). In contrast, McLeod et al (2003) did not observe a correlation between the GSTP1-Ile105Val polymorphism and response to oxaliplatin-based chemotherapy in colorectal cancer patients (McLeod et al, 2003). These controversial results in colorectal cancer may indicate a lower impact of the GSTP1-Ile105Val polymorphism in oxaliplatin-based chemotherapy regimens. Cabelguenne et al (2001) could not observe a correlation between GSTP1 genotypes and response to cisplatin neoadjuvant chemotherapy in head and neck squamous cell cancer (HNSCC) patients. However, they described that low plasmatic GSTP1 levels conferred to a 2.3-fold increased relative risk of complete response in HNSCC patients (Cabelguenne et al, 2001).

In summary, the results we report here are in strong agreement with the current understanding of GSTP1 involvement in cisplatin detoxification. Our findings support the hypothesis that increased cisplatin sensitivity may in part be due to impaired GSTP1 enzyme function. However, a critical review of our results in conjunction with the current literature revealed that analysis of only the GSTP1 polymorphism does not represent a valid approach to distinguish responders from nonresponders to a combination chemotherapy of 5-FU and cisplatin. Reasons are the static character that is inherent to a polymorphism and the complexity of metabolising 
steps for chemotherapeutics. Therefore, we investigated a panel of nine genes involved in 5-FU and cisplatin metabolism.

Considering the known interactions between GST genotypes, we also analysed GSTM1 and GSTT1 genotypes, but did not find any correlation with clinical characteristics. Polymorphisms in ERCC1 and ERCC2 also did not show any correlation with clinical outcome in this study. One reason for this result maybe the limited number of patients in the retrospective analysis.

For a more accurate prediction of response and survival to the combination treatment of 5-FU and cisplatin, we also aimed to explore possible associations between polymorphisms in fluoropyrimidine metabolism and clinical outcome.

The active metabolites of fluoropyrimidines exert their antitumour activity mainly through TS inhibition. This reaction is facilitated by the formation of a ternary complex consisting of TS, 5,10-Methylene THF and 5-fluoro-dUMP (Peters et al, 2002). There is growing evidence for functionally important polymorphic variations within the TS gene. The $28-\mathrm{bp}$ repeat and the $\mathrm{G} / \mathrm{C}$ SNP within the $5^{\prime}$ UTR of the gene as well as the $6 \mathrm{bp}$ deletion polymorphism in the $3^{\prime}$ UTR, all have been described to alter expression of TS (Pullarkat et al, 2001; Kawakami and Watanabe, 2003; Mandola et al, 2003, 2004). In the current study, patients who possessed a TS $5^{\prime}$ genotype associated with low TS mRNA expression levels (Mandola et al, 2003) demonstrated a trend for superior survival time compared with patients harbouring TS genotypes known to be associated with high TS mRNA expression. This observation is in agreement with recent findings by Marcuello et al (2004) who revealed a significant association between clinical outcome to 5-FU-based chemotherapy in colorectal cancer and TS polymorphisms only if both TS polymorphisms within the $5^{\prime}$ UTR were analysed in conjunction (Marcuello et al, 2004). A trend between TS polymorphism and clinical outcome was observed by Ishida et al (2002) in gastric cancer patients who received oral fluoropyrimidine therapy. However, the authors did not include the novel G/C SNP that functionally transfers a TS 3R genotype into a TS $2 \mathrm{R}$ genotype in their analysis. Although the observed association between TS polymorphisms and outcome in our study did not reach significance, the results support the hypothesis that a comprehensive analysis of these TS polymorphisms is needed if associations between TS polymorphisms and response to fluoropyrimidine chemotherapy is explored. The reason that the observed effect did not reach statistical significance may be again due to the small number of patients.

Based on these findings, favourable and unfavourable genotype groups were defined to describe the clinical outcome to 5-FU/ cisplatin combination chemotherapy in gastric cancer. We could demonstrate that a patient's benefit of 5-FU/cisplatin chemotherapy significantly increases with the number of favourable genotypes. A combined analysis may more accurately identify patients with maximum benefit from therapy. Although the number of patients possessing two favourable genotypes was small in our study their median survival time reached almost 24 months. These findings, if confirmed, may have a significant impact on the management of gastric cancer patients, since alternative drug combinations are becoming available.

Our study is limited by both its retrospective nature and the relatively small sample size. In addition, meanwhile more polymorphic genes involved in platinum and 5-FU metabolism have been identified (e.g. ERCC1-C8092A, MTHFR-A1298C), that may also impact the effect of these drugs. To confirm our findings from this pilot study and to improve the predictive value of pharmacogenetic analyses in gastric cancer patients, we are currently analysing a panel of 26 polymorphisms in genes of metabolising and DNA repair enzymes in a large, randomised, prospective phase III trial in advanced gastric cancer, involving more than 220 patients.

To conclude, this pilot study demonstrated that combined genotype analysis of GSTP1, TS-5' $28 \mathrm{bp}$ and TS-5' G $\rightarrow$ C polymorphisms may contribute to the selection of gastric cancer patients who would benefit most from 5-FU/cisplatin combination chemotherapy. To our knowledge, this is the first report demonstrating a predictive value of GSTP1 genotypes in regard to 5-FU/cisplatin combination chemotherapy in gastric cancer patients.

\section{REFERENCES}

Al-Batran SE, Atmaca A, Hegewisch-Becker S, Jaeger D, Hahnfeld S, Rummel MJ, Seipelt G, Rost A, Orth J, Knuth A, Jaeger E (2004) Phase II trial of biweekly infusional fluorouracil, folinic acid, and oxaliplatin in patients with advanced gastric cancer. J Clin Oncol 22: 658-663

Arand M, Muhlbauer R, Hengstler J, Jager E, Fuchs J, Winkler L, Oesch F (1996) A multiplex polymerase chain reaction protocol for the simultaneous analysis of the glutathione S-transferase GSTM1 and GSTT1 polymorphisms. Anal Biochem 236: 184-186

Ban N, Takahashi Y, Takayama T, Kura T, Katahira T, Sakamaki S, Niitsu Y (1996) Transfection of glutathione S-transferase (GST)-pi antisense complementary DNA increases the sensitivity of a colon cancer cell line to adriamycin, cisplatin, melphalan, and etoposide. Cancer Res 56: $3577-3582$

Boku N, Chin K, Hosokawa K, Ohtsu A, Tajiri H, Yoshida S, Yamao T, Kondo H, Shirao K, Shimada Y, Saito D, Hasebe T, Mukai K, Seki S, Saito H, Johnston PG (1998) Biological markers as a predictor for response and prognosis of unresectable gastric cancer patients treated with 5-fluorouracil and cis-platinum. Clin Cancer Res 4: 1469-1474

Bouche O, Raoul JL, Bonnetain F, Giovannini M, Etienne PL, Lledo G, Arsene D, Paitel JF, Guerin-Meyer V, Mitry E, Buecher B, Kaminsky MC, Seitz JF, Rougier P, Bedenne L, Milan C (2004) Randomized multicenter phase II trial of a biweekly regimen of fluorouracil and leucovorin (LV5FU2), LV5FU2 plus cisplatin, or LV5FU2 plus irinotecan in patients with previously untreated metastatic gastric cancer: a FEDERATION Francophone de Cancerologie Digestive Group Study-FFCD 9803. J Clin Oncol 22: 4319-4328

Cabelguenne A, Loriot MA, Stucker I, Blons H, Koum-Besson E, Brasnu D, Beaune P, Laccourreye O, Laurent-Puig P, De Waziers I (2001)
Glutathione-associated enzymes in head and neck squamous cell carcinoma and response to cisplatin-based neoadjuvant chemotherapy. Int J Cancer 93: 725 - 730

Chao Y, Yeh KH, Chang CJ, Chen LT, Chao TY, Wu MF, Chang CS, Chang JY, Chung CY, Kao WY, Hsieh RK, Cheng AL (2004) Phase II study of weekly oxaliplatin and 24-h infusion of high-dose 5-fluorouracil and folinic acid in the treatment of advanced gastric cancer. Br J Cancer 91: $453-458$

Cohen V, Panet-Raymond V, Sabbaghian N, Morin I, Batist G, Rozen R (2003) Methylenetetrahydrofolate reductase polymorphism in advanced colorectal cancer: a novel genomic predictor of clinical response to fluoropyrimidine-based chemotherapy. Clin Cancer Res 9: 1611-1615

Danenberg PV (1977) Thymidylate synthetase - a target enzyme in cancer chemotherapy. Biochim Biophys Acta 473: 73-92

Etienne MC, Formento JL, Chazal M, Francoual M, Magne N, Formento P, Bourgeon A, Seitz JF, Delpero JR, Letoublon C, Pezet D, Milano G (2004) Methylenetetrahydrofolate reductase gene polymorphisms and response to fluorouracil-based treatment in advanced colorectal cancer patients. Pharmacogenetics 14: 785-792

Frosst P, Blom HJ, Milos R, Goyette P, Sheppard CA, Matthews RG, Boers GJ, den Heijer M, Kluijtmans LA, van den Heuvel LP, Rozen R (1995) A candidate genetic risk factor for vascular disease: a common mutation in methylenetetrahydrofolate reductase. Nat Genet 10: 111-113

Goto S, Iida T, Cho S, Oka M, Kohno S, Kondo T (1999) Overexpression of glutathione S-transferase pi enhances the adduct formation of cisplatin with glutathione in human cancer cells. Free Radic Res 31: 549-558

Horie N, Aiba H, Oguro K, Hojo H, Takeishi K (1995) Functional analysis and DNA polymorphism of the tandemly repeated sequences in the 
$5^{\prime}$-terminal regulatory region of the human gene for thymidylate synthase. Cell Struct Funct 20: $191-197$

Iacopetta B, Grieu F, Joseph D, Elsaleh H (2001) A polymorphism in the enhancer region of the thymidylate synthase promoter influences the survival of colorectal cancer patients treated with 5-fluorouracil. $\mathrm{Br} \mathrm{J}$ Cancer 85: 827-830

Ishida Y, Kawakami K, Tanaka Y, Kanehira E, Omura K, Watanabe G (2002) Association of thymidylate synthase gene polymorphism with its mRNA and protein expression and with prognosis in gastric cancer. Anticancer Res 22: 2805-2809

Isla D, Sarries C, Rosell R, Alonso G, Domine M, Taron M, Lopez-Vivanco G, Camps C, Botia M, Nunez L, Sanchez-Ronco M, Sanchez JJ, Lopez-Brea M, Barneto I, Paredes A, Medina B, Artal A, Lianes P (2004) Single nucleotide polymorphisms and outcome in docetaxelcisplatin-treated advanced non-small-cell lung cancer. Ann Oncol 15: $1194-1203$

Joshi MB, Shirota Y, Danenberg KD, Conlon DH, Salonga DS, Herndon II JE, Danenberg PV, Harpole Jr DH (2005) High gene expression of TS1, GSTP1, and ERCC1 are risk factors for survival in patients treated with trimodality therapy for esophageal cancer. Clin Cancer Res 11: $2215-2221$

Kaplan E, Meier P (1958) Nonparametric estimation from incomplete observations. JAMA 53: 457-481

Kawakami K, Omura K, Kanehira E, Watanabe Y (1999) Polymorphic tandem repeats in the thymidylate synthase gene is associated with its protein expression in human gastrointestinal cancers. Anticancer Res 19: $3249-3252$

Kawakami K, Watanabe G (2003) Identification and functional analysis of single nucleotide polymorphism in the tandem repeat sequence of thymidylate synthase gene. Cancer Res 63: 6004-6007

Lee SH, Kang WK, Park J, Kim HY, Kim JH, Lee SI, Park JO, Kim K, Jung CW, Park YS, Im YH, Lee MH, Park K (2004) Combination chemotherapy with epirubicin, docetaxel and cisplatin (EDP) in metastatic or recurrent, unresectable gastric cancer. $\mathrm{Br} J$ Cancer 91 $18-22$

Leichman L, Lenz HJ, Leichman CG, Groshen S, Danenberg K, Baranda J, Spears CP, Boswell W, Silberman H, Ortega A (1995) Quantitation of intratumoral thymidylate synthase expression predicts for resistance to protracted infusion of 5-fluorouracil and weekly leucovorin in disseminated colorectal cancers: preliminary report from an ongoing trial. Eur J Cancer 31A: 1306-1310

London SJ, Yuan JM, Chung FL, Gao YT, Coetzee GA, Ross RK, Yu MC (2000) Isothiocyanates, glutathione S-transferase M1 and T1 polymorphisms, and lung-cancer risk: a prospective study of men in Shanghai, China. Lancet 356: $724-729$

Lunn RM, Helzlsouer KJ, Parshad R, Umbach DM, Harris EL, Sanford KK, Bell DA (2000) XPD polymorphisms: effects on DNA repair proficiency. Carcinogenesis 21: $551-555$

Mandola MV, Stoehlmacher J, Muller-Weeks S, Cesarone G, Yu MC, Lenz HJ, Ladner RD (2003) A novel single nucleotide polymorphism within the $5^{\prime}$ tandem repeat polymorphism of the thymidylate synthase gene abolishes USF-1 binding and alters transcriptional activity. Cancer Res 63: $2898-2904$

Mandola MV, Stoehlmacher J, Zhang W, Groshen S, Yu MC, Iqbal S, Lenz HJ, Ladner RD (2004) A 6 bp polymorphism in the thymidylate synthase gene causes message instability and is associated with decreased intratumoral TS mRNA levels. Pharmacogenetics 14: 319-327

Marcuello E, Altes A, del Rio E, Cesar A, Menoyo A, Baiget M (2004) Single nucleotide polymorphism in the $5^{\prime}$ tandem repeat sequences of thymidylate synthase gene predicts for response to fluorouracil-based chemotherapy in advanced colorectal cancer patients. Int J Cancer 112: $733-737$

Marsh S, McKay JA, Cassidy J, McLeod HL (2001) Polymorphism in the thymidylate synthase promoter enhancer region in colorectal cancer. Int J Oncol 19: 383-386
McLeod HL, Sargent DJ, Marsh S, Fuchs C, Ramanathan RK, Williamson S, Findlay B, Thibodeau S, Petersen G, Goldberg R (2003) Pharmacogenetic analysis of systemic toxicity and response after 5-fluorouracil (5FU)/ CPT-11, 5FU/oxaliplatin (oxal), or CPT-11/oxal therapy for advanced colorectal cancer (CRC): Results from an intergroup trial. Proc Am Soc Clin Oncol 22: 253, (abstr 1013)

Miller R (1981) Survival Analyses. New York: John Wiley \& Sons

Oguri T, Fujiwara Y, Katoh O, Daga H, Ishikawa N, Fujitaka K, Yamasaki M, Yokozaki M, Isobe T, Ishioka S, Yamakido M (2000) Glutathione Stransferase-pi gene expression and platinum drug exposure in human lung cancer. Cancer Lett 156: 93 -99

Park DJ, Stoehlmacher J, Zhang W, Tsao-Wei DD, Groshen S, Lenz HJ (2001) A Xeroderma pigmentosum group D gene polymorphism predicts clinical outcome to platinum-based chemotherapy in patients with advanced colorectal cancer. Cancer Res 61: 8654-8658

Park YH, Ryoo BY, Choi SJ, Kim HT (2004) A phase II study of capecitabine and docetaxel combination chemotherapy in patients with advanced gastric cancer. Br J Cancer 90: 1329-1333

Parkin DM (2001) Global cancer statistics in the year 2000. Lancet Oncol 2: $533-543$

Peters GJ, Backus HH, Freemantle S, van Triest B, Codacci-Pisanelli G, van der Wilt CL, Smid K, Lunec J, Calvert AH, Marsh S, McLeod HL, Bloemena E, Meijer S, Jansen G, van Groeningen CJ, Pinedo HM (2002) Induction of thymidylate synthase as a 5-fluorouracil resistance mechanism. Biochim Biophys Acta 1587: 194-205

Pullarkat ST, Stoehlmacher J, Ghaderi V, Xiong YP, Ingles SA, Sherrod A, Warren R, Tsao-Wei D, Groshen S, Lenz HJ (2001) Thymidylate synthase gene polymorphism determines response and toxicity of 5-FU chemotherapy. Pharmacogenomics J 1: 65-70

Shen MR, Jones IM, Mohrenweiser H (1998) Nonconservative amino acid substitution variants exist at polymorphic frequency in DNA repair genes in healthy humans. Cancer Res 58: 604-608

Shirota Y, Stoehlmacher J, Brabender J, Xiong YP, Uetake H, Danenberg KD, Groshen S, Tsao-Wei DD, Danenberg PV, Lenz HJ (2001) ERCC1 and thymidylate synthase mRNA levels predict survival for colorectal cancer patients receiving combination oxaliplatin and fluorouracil chemotherapy. J Clin Oncol 19: 4298-4304

Souglakos J, Syrigos K, Potamianou A, Polyzos A, Boukovinas I, Androulakis N, Kouroussis C, Vardakis N, Christophilakis C, Kotsakis A, Georgoulias V (2004) Combination of irinotecan (CPT-11) plus oxaliplatin (L-OHP) as first-line treatment in locally advanced or metastatic gastric cancer: a multicentre phase II trial. Ann Oncol 15: $1204-1209$

Stoehlmacher J, Park DJ, Zhang W, Groshen S, Tsao-Wei DD, Yu MC, Lenz HJ (2002) Association between glutathione S-transferase P1, T1, and M1 genetic polymorphism and survival of patients with metastatic colorectal cancer. J Natl Cancer Inst 94: 936 - 942

Stoehlmacher J, Park DJ, Zhang W, Yang D, Groshen S, Zahedy S, Lenz HJ (2004) A multivariate analysis of genomic polymorphisms: prediction of clinical outcome to 5-FU/oxaliplatin combination chemotherapy in refractory colorectal cancer. Br J Cancer 91: $344-354$

Ulrich CM, Bigler J, Velicer CM, Greene EA, Farin FM, Potter JD (2000) Searching expressed sequence tag databases: discovery and confirmation of a common polymorphism in the thymidylate synthase gene. Cancer Epidemiol Biomarkers Prev 9: $1381-1385$

Van Cutsem E (2004) The treatment of advanced gastric cancer: new findings on the activity of the taxanes. Oncologist 9(Suppl 2): 9-15

Watson MA, Stewart RK, Smith GB, Massey TE, Bell DA (1998) Human glutathione S-transferase P1 polymorphisms: relationship to lung tissue enzyme activity and population frequency distribution. Carcinogenesis 19: $275-280$

Zimniak P, Nanduri B, Pikula S, Bandorowicz-Pikula J, Singhal SS, Srivastava SK, Awasthi S, Awasthi YC (1994) Naturally occurring human glutathione S-transferase GSTP1-1 isoforms with isoleucine and valine in position 104 differ in enzymic properties. Eur J Biochem 224: 893-899 